\title{
Effectiveness of reality therapy on adjustment in female adolescents with anxiety
}

\begin{abstract}
Background and purpose: our country is one of young and developing countries with a considerable number of students, especially high school students who pass the critical period of adolescence. The aim of this study was to investigate effectiveness of reality therapy on adjustment of female adolescents with anxiety.
\end{abstract}

Methodology: The research method was experimental with pre-test, post-test, and control group. Population includes all female high school students in Shirvan city during ay 2005. Using convenience purposive sampling 20 students with high anxiety scores in Depression, Anxiety, Stress Scale (DASS-21) were selected and then randomly assigned to two experimental and control groups ( $\mathrm{n}=10$ in each group). The experimental group took eight reality therapy sessions of 2 hours based on standard manual. The instrument used in this study was the Adjustment Inventory for School Students filled out by experimental and control groups during the pre-test and posttest. Data were analyzed using SPSS software and covariance analysis.

Results: The results indicated the effectiveness of reality therapy in increasing overall consistency as well as emotional, social and educational adjustment in the experimental group compared with the control group $(\mathrm{P}<0.001)$

Conclusion: Because adolescence is associated with inconsistencies, according to the results, the reality therapy can be used as an effective method to increase adjustment among adolescent girls

Keywords: reality therapy, adolescent girls, adjustment, anxiety
Volume 3 Issue 2 - 2017

\section{Vahidiborji G, Jadidi M, Donyavi R}

Department of Clinical Psychology, Islamic Azad University, Iran

Correspondence: Mohsen Jadidi, Assistant Professor, Islamic Azad University, Bandar Gaz Branch, Iran, Tel +989|23000074, Email Jadidi.Mohsen@gmail.com

Received:September 04, 2016 | Published: March 10, 2017

\section{Introduction}

Adolescence is one of the most important periods of life, a transitional period in which a person moves from the childhood safety towards responsibility and privileges of adulthood. ${ }^{1}$ In this period, due to puberty, the individual faces rapid changes in body and emotions. ${ }^{2}$ Estimations show that the largest generation of adolescents in terms of number belongs to present time in Iran. ${ }^{3}$ According to the latest census conducted by the Statistical Center of Iran in 2011, teens constitute almost 15 million people (12.9 percent) of the total population. ${ }^{4}$

The changes in this period of development could potentially form specific problems. When adolescents are not able to successfully overcome the crisis and the developmental challenges, they will experience psychological distress and significant disruption in everyday life and this could lead to confusion and frustration. ${ }^{5}$ Anxiety is one of the most common psychiatric disorders in adolescence. ${ }^{6}$ Some authors report that the puberty in adolescence is accompanied with physiological changes and this could cause multifaceted challenges. ${ }^{7}$ In addition, in early adolescence, anxiety could influence interpersonal sensitivity and dwindling of adaptability. The process challenge adjustment of juveniles and may result in stress and anxiety. So, anxious adolescents experience more psychological problems than their peers. ${ }^{8}$

To counter these wide biosociopsychological changes and transformations, it is important for adolescents to achieve appropriate adjustment strategies and coping styles to deal with life demands. ${ }^{9}$ In this regard, Poul (2004) also believes that adjustment requires change, modification as well as an attempt to restraining tensions effectively.
This has a special importance for adolescents who must face with juvenile stresses.

Among of different therapeutic approaches, reality therapy is more known for working with adolescents in educational settings. Among the latest counseling and psychotherapy approaches, reality therapy is based on choice and control theory and considers psychological problems as coming from choices made by individuals. In this approach people meet their basic needs through making better choices. In fact, the main objective of reality therapy approach is helping people to be aware of their needs, monitor behavior, and make appropriate decisions. ${ }^{10}$

Given that this short-term treatment can be applied to group in schools, a large number of adolescents can be treated at the same time. This study attempts to measure the effectiveness of reality therapy on adjustment of female adolescent students with anxiety.

\section{Methods}

This study is applied and was conducted in quasi-experimental format with pre- test and post-test design, with experimental and control groups. The study population included all high school students at Hazrate Maryam high school in Shirvan in the second semester of 2015 ay. The sampling method in the first step done based on "convenience purposive sampling method". In this regard, the DASS questionnaire was distributed to all students and then, only those who gain sore up to 7 participate in the project and possessing other inclusion criteria were selected; in this manner, 20 subjects were selected and assigned randomly into control and experimental groups. Instruments were the "Depression, Anxiety, Stress Scale" 
and "Adjustment Inventory for School Students, Sinha and Singh" The Depression, Anxiety, Stress Scale, DASS ${ }^{11}$ is a series of three self-reported subscales which measure states of negative affects in depression, anxiety and stress. This scale measures the severity of main symptoms of depression, anxiety and stress. To complete the questionnaire, individuals must identify their states during the latest week. Since this scale could provide a comparison of the severity of symptoms over several weeks, it can be used to assess the progress of treatment over time. Antony and colleagues (1998) performed a factor-analysis on the scale where the results of their research again indicated three factors of depression, anxiety and stress. The results of this study showed that 68 percent of the total variance of the scale explain by these three factors. The validity and reliability of the questionnaire in Iran has been studied so that the test-retest reliability for depression, anxiety and stress was reported 80/0, 76/0 and 77/0, respectively, and Cronbach's alpha coefficients for depression, anxiety and stress were 81/0,74/0 and 78/0, respectively. Each of the subscales of DASS includes 7 questions where final score of any item is the sum of its question scores (Table 1). ${ }^{11}$

Table I Mean and standard deviation of adjustment variable in both control and experimental groups

\begin{tabular}{|c|c|c|c|c|}
\hline \multirow[t]{6}{*}{ Emotional Adjustment } & Experimental group & & $\mathbf{M}$ & SD \\
\hline & & Pre- test & $30 / 26$ & $2 / 05$ \\
\hline & & Post- test & $23 / 33$ & $83 / 3$ \\
\hline & & Follow up & $90 / 29$ & $3 / 14$ \\
\hline & Control group & Pre- test & $7 / 12$ & $96 / 3$ \\
\hline & & Post- test & $66 / 7$ & $56 / 3$ \\
\hline \multirow[t]{5}{*}{ Social Adjustment } & Experimental group & Pre- test & $43 / 26$ & $44 / 2$ \\
\hline & & Post- test & $70 / 29$ & $44 / 3$ \\
\hline & & Follow up & $30 / 29$ & $00 / 2$ \\
\hline & Control group & Pre- test & $70 / 7$ & $31 / 2$ \\
\hline & & Post- test & $00 / 8$ & $72 / 2$ \\
\hline \multirow[t]{5}{*}{ Educational Adjustment } & Experimental group & Pre- test & 25 & $90 / 2$ \\
\hline & & Post- test & $14 / 30$ & $77 / 1$ \\
\hline & & Follow up & $45 / 29$ & $2 / 17$ \\
\hline & Control group & Pre- test & $8 / 14$ & $48 / 3$ \\
\hline & & Post- test & $62 / 8$ & $3 / 30$ \\
\hline
\end{tabular}

Adjustment inventory has been edited by Sinha and Singh and translated and rewritten by Karami in Iran. The inventory has 60 questions and the answer for each has been designed as 'Yes' or 'No.' The reliability coefficients for this test, using the split half and testretest, were reported as 0.95 and 0.93 , respectively. The validity of this test has been confirmed by a team of psychologists. The content and formal validity of this questionnaire has been confirmed by three professors of consultation, psychometrics and statistics. They have confirmed that the questionnaire is certifiable for assessing the adjustment of high school and pre-university students in three areas: emotional, social and educational. According to Karami, the reliability of this inventory through the split half method for emotional adjustment was 0.94 and for social adjustment 0.93 , respectively. This questionnaire seeks to discriminate the high school students (aged 14 to 18) with good adjustment from students with poor adjustment in three areas: emotional, social and educational.

\section{Inclusion criteria for the study}

a. A score higher than 7 on the subscale of anxiety in the DASS-21.

b. Not receiving any other psychological treatments. c. Willingness to participate in group therapy sessions and administration of consensus form.

\section{The exclusion criteria were as following}

a. Evidence of severe illness in person.

b. Absence for more than two sessions during group therapy.

c. The participants can stop attending for any personal reason.

\section{Findings}

Frequency for experimental and control groups, was for each of 10 adolescents with anxiety that were randomly assigned in two groups of 10 subjects into experimental and control groups. All subjects were also matched in terms of age, so that the 14-year-old girls are used in this study. For investigating the training effect, mean and standard deviation of adjustment variable in both control and experimental groups, are shown in Table 1. The results indicate an increase in the adjustment subscale scores (emotional, social and educational) as a result of the post-test and follow-up in the experimental group while there was no any significant modification in the scores of control group subjects. 
The multivariate analysis of covariance (MANCOVA) was used to investigate the effectiveness of the reality therapy. In this study, Shapiro-Wilk test was used to determine normality. In the end, $p>0.05$ is the sign of test normality.

Using analysis of covariance to determine the effectiveness of reality therapy on adjustment in the experimental group, the results showed that there are significant differences between the mean scores of emotional adjustment, social adjustment and academic adjustment subscales in the post-test of experimental group and the control group, $(\mathrm{P}<0.001)$. Also, since this influence is significant in followup in $\mathrm{P}<0.001$, it is suggested that the influence of this treatment on enhancing adjustment (emotional, social and educational) has remained. This means that the reality therapy improves emotional, social and educational adjustment in the subjects with anxiety.
Table 2 Normality test for post-test scores

\begin{tabular}{llll}
\hline Variable & & df & Sig \\
\hline Emotional Adjustment & Experimental group & 10 & $92 / 0$ \\
& Control group & 10 & 0.53 \\
Social Adjustment & Experimental group & 10 & 0.06 \\
& Control group & 10 & 0.07 \\
Educational Adjustment & Experimental group & 10 & $25 / 0$ \\
& Control group & 10 & $11 / 0$ \\
\hline
\end{tabular}

Table 3 Results of Analysis of covariance in effectiveness of reality therapy on the adjustment of adolescent girls in post-test and follow-up

\begin{tabular}{|c|c|c|c|c|c|c|c|}
\hline Variables & Phase & Source of variation & df & $\mathbf{F}$ & $\propto$ & $\mathbf{R}^{2}$ & $\beta$ \\
\hline \multirow[t]{6}{*}{ Emotional Adjustment } & Post-test & Pre- test & I & $96 / 114$ & $001 / 0$ & $87 / 0$ & I \\
\hline & & Groups & I & $24 / 20$ & $001 / 0$ & $54 / 0$ & $988 / 0$ \\
\hline & & Error & 17 & & & & \\
\hline & Follow up & Pre- test & I & $89 / 80$ & $001 / 0$ & $82 / 0$ & 1 \\
\hline & & Groups & I & $73 / 9$ & $001 / 0$ & $36 / 0$ & $83 / 0$ \\
\hline & & Error & 17 & & & & \\
\hline \multirow[t]{6}{*}{ Social Adjustment } & Post-test & Pre- test & I & $123 / 0$ & $001 / 0$ & $91 / 0$ & 1 \\
\hline & & Groups & I & $43 / 26$ & $001 / 0$ & $58 / 0$ & $98 / 0$ \\
\hline & & Error & 17 & & & & \\
\hline & Follow up & Pre- test & I & $76 / 93$ & $001 / 0$ & $85 / 0$ & I \\
\hline & & Groups & I & $32 / 11$ & $001 / 0$ & $39 / 0$ & $86 / 0$ \\
\hline & & Error & 17 & & & & \\
\hline \multirow[t]{6}{*}{ Educational Adjustment } & Post-test & Pre- test & I & $85 / 107$ & $001 / 0$ & $86 / 0$ & I \\
\hline & & Groups & I & $27 / 18$ & $001 / 0$ & $524 / 0$ & $973 / 0$ \\
\hline & & Error & 17 & & & & \\
\hline & Follow up & Pre- test & I & $86 / 0$ & $001 / 0$ & $83 / 0$ & I \\
\hline & & Groups & I & $10 / 02$ & $001 / 0$ & $372 / 0$ & $843 / 0$ \\
\hline & & Error & 17 & & & & \\
\hline
\end{tabular}

\section{Discussion}

The results showed the reality therapy has improved adjustment in the subjects. It was also shown in this study that reality therapy is effective on three subscales: emotional adjustment, social adjustment and academic adjustment. These results are consistent with Mehrbakhsh (2010) which indicated the effectiveness of reality therapy on emotional, social, and educational adjustment, Armstrong and colleagues (2005) which indicated the effectiveness of group counseling based on reality therapy in increasing responsibility and academic performance, Asner and Kabrely (1983) which indicated the effectiveness of reality therapy on academic success and passion for education, Chunk (1994) which indicated the effectiveness of reality therapy on improvement of social and communication skills,
Farzam (2001) which indicated the effectiveness of reality therapy on academic performance.

One of the main components related to emotional adjustment and mental health of adolescents is the acceptance of responsible behavior. Emphasizing acceptance of responsibility and meeting the basic needs, reality therapy leads to a more self-awareness which in turn grants the adolescent a deep comprehension of her/ his emotions, weak points, powers and needs, and make her able to evaluate, conduct and control the life events where these capabilities play a clear role in development of insight and intuition toward the self and surrounding environment, and promote the individual compatibility in emotional terms and protects the individual from being dominated by emotions. Therefore, training of reality therapy leads to emotional adjustment in adolescent female students. ${ }^{12}$ 
Concerning social adjustment, it can also be explained that in accordance with reality therapy features that are based on comprehension, responsibility and meeting of needs, this therapy enhances the emotional perception of individuals and this level of perception is accompanied by power enhancement, evaluation of environmental stimuli, increasing the power of establishment of social and affective relations and expression of organized functioning empathy for person, which provides the necessary mental setting for achieving social adjustment. ${ }^{13}$ With regards to training of reality therapy through organization of thoughts, memory and memory content, individual faces more integrated with issues and tensions related to social environment. Furthermore, the emotional facilitation with positive behavioral changes helps individual to better adapt with environment and environmental stimuli. Also through emotional cognition, individuals are applied for increasing the probability of correct and realistic cognition of emotions and stressful situations; that is, emotional cognition, through predictive mechanisms, controls and efficient coping styles, helps improve the quality of social communications and achieve appropriate social adjustment. ${ }^{14}$

Concerning educational adjustment, it can also be explained that high anxiety today is known as a disruptive phenomenon that prevents the individual from establishing communication with others and from considering himself/herself responsible for anything. Reality therapy is an approach applicable to various school problems and educational issues. This approach tries to help adolescents understand reasons and motives for their behaviors and helps them evaluate and investigate their behaviors. ${ }^{15}$ In fact, this approach is a composition of existential beliefs and behavioral techniques which emphasize responsibility and control. These two are personality variables that have a positive association with educational and academic adjustment; on the other hand, reality therapy leads the students to believe that, under any circumstances, they themselves are responsible for fulfilling their needs in the end, that this training optimizes the appreciation of the importance of their surrounding environmental issues such as educational issues to satisfy their needs and earn sufficient motivation for more adjustment.

\section{Conclusion}

The training of reality therapy method is effective on emotional adjustment, social adjustment and educational adjustment in adolescent girls with anxiety.

\section{Acknowledgements}

None.

\section{Conflict of interest}

The author declares no conflict of interest.

\section{References}

1. Mogler C. The physical, cognitive, social, personality, moral and faith development of adolescence. 2009.
2. Corey G. Theory and practice of group counselling. 8th ed. USA: Californiation Books/ Cole publishing company; 2002.

3. UNFPA. State of the World Population 2003. Making 1 Billion Count: Investing. In: Unni, et al. editors. Stress, sense of coherence and emotional symptoms in adolescents, Psychology \& Health. 2006;29(1):32-49.

4. Statistical Center of Iran. Information technology 2009. Iran. 2011.

5. Garber J, Keily MK, Martin NC. Development of adolescence depressive symptoms: predictors of changes. J Consult Clin Psychol. 2002;70(1):79-95.

6. Jalaliaria K. An Investigation of Parents' and Teachers' Knowledge about Puberty Health and their Attitudes about How to Teach it to The Girl Students in Gorgan High School 2003. Shahid Beheshti University of Medical Sciences and Health Service. Faculty of Nursing and Midwifery. Thesis for MS Degree in Midwifery. 2004.

7. Ghoraii H, Malek Afzali H, Ramezani Tehrani F, et al. The needs of girl's students of medicine group about Reproductive health education by focus group discussion method in Tehran 1379-80. Teb Tazkiyeh. 2003;11(4):22-7.

8. Xiu Hong M, Fang Biao T, Yu Hui W, et al. Coping as a Mechanism Linking Stressful Life Events and Mental Health Problems in Adolescents. Biomed Environ Sci. 2011;24(6):649-655.

9. Nina R, Sylvie M, Kimberly G. Spiritual Coping and Psychosocial Adjustment of Adolescents with Chronic illness: The Role of Cognitive Attributions, Age, and Disease Group. Journal of Adolesc Health. 2013;52(5):559-565.

10. Kakia L. Effect of group counseling based on reality therapy on identity crisis in students of guidance schools. $J$ Fundament Mental Health. 2010;12(1):430-437.

11. Lovibond SH, Lovibond PF. Manual for the Depression Anxiety Stress Scales. 2nd ed. Psychology Foundation of Australia, Sydney, Australia, 1995.

12. Aliakbarzadeh Arani Z, Taghavi T, Sharifi N, et al. Impact of training on social adaptation in mothers of educable mentally-retarded children based on Roy adaptation theory. Feyz Journal of Kashan University of Medical Sciences. 2012;16(2):128-134.

13. Rahimi J, Haghighi J, Mehrabizadeh Honarmand M, et al. Effect of assertiveness training on social skills, social anxiety and selfexpression in grade one boy's students' secondary school. J Edu Sci Psy. 2007;13(1):111-124.

14. Ranjbarkohn Z, Sajadinejad MS. Effect of assertiveness training on self-esteem and depression in students of Isfahan University of Medical Sciences. J Birjand Univ Med Sci. 2010;17(4):308-315.

15. Narimani M. A Survey on the incidence rate of anxiety in students \& comparing the effectiveness of beck cognitive behavioral model with Meichanbaum mental inoculation model in decreasing anxiety amongst them. Daneshvar Med. 2001;8(33):101-123.

16. Wubbolding RE. Reality Therapy for the 21st century. Philadelphia, USA: Brunner Routledg; 2000. 